Check for updates

Cite this: RSC Adv., 2018, 8, 23606

\title{
Tribological properties of synthetic base oil containing polyhedral oligomeric silsesquioxane grafted graphene oxide
}

\author{
Bo Yu, ${ }^{a}$ Kai Wang, ${ }^{\text {ab }}$ Yiwen Hu, ${ }^{b}$ Feng Nan, ${ }^{b}$ Jibin $\mathrm{Pu}^{\text {*b }}$ Haichao Zhao (DD *b \\ and Pengfei Juc
}

The dispersion of graphene-based materials in lubricating oil is a prerequisite for improving its friction and wear performance. In this study, polyhedral oligomeric silsesquioxane (POSS) grafted graphene oxide (GO) was synthesized with an aim to improve the dispersibility of graphene in synthetic base oil. The composition and morphology of POSS-GO conjugates were characterized by FTIR, XPS, Raman spectroscopy, TEM and SPM. The tribological behavior of base oil with various concentrations of POSS-GO were examined using a UMT-3 friction and wear tester, and the worn surfaces were analyzed using Raman spectroscopy. It was found that concentrations of POSS-GO additives in the base oil is an important aspect for decreasing the friction and wear of the lubricated solid contacts. At lower and higher concentrations of POSS-GO, the lubricating effect is not effective or even worse. In contrast, at optimized concentration of POSS-GO, graphene sheets could form a boundary tribofilm between the contact, resulting in reduction of the friction coefficient and wear.

Received 29th May 2018

Accepted 20th June 2018

DOI: $10.1039 / \mathrm{c} 8 \mathrm{ra0} 4593 \mathrm{c}$

rsc.li/rsc-advances generally recognized that the tribological performance of graphene depends largely on its dispersibility in base oil. ${ }^{10}$ To attain better tribological behavior, many approaches were used to improve graphene's dispersion in lubricant oils. Due to other nanostructure's extra steric hindrance effect, reduced GO could get better dispersibility and provide lower friction coefficients and better wear resistance. ${ }^{11,12}$ Yang et al. have proposed that carbon nanotubes (CNTs) seem to reduce the $\pi-\pi$ stacking and agglomeration in graphene nanoplatelets. ${ }^{13}$ Dou et al. reported that crumpled graphene balls as additive with 0.01-0.1 wt\% concentrations can significantly improve the lubrication properties of polyalphaolefin base oil. ${ }^{14}$ Chemical modification was also used to improve graphene's dispersibility in base oil. Lin et al. revealed that modified graphene platelets with stearic and oleic acids could lead to an improvement in the dispersion of graphene platelets in base oil. The results indicated that $0.075 \mathrm{wt} \%$ of modified graphene plates in base oil could show excellent tribological performance. ${ }^{15}$ Peng et al. found that antiwear ability of modified graphene plates were also correlated strongly with the structure. ${ }^{16}$

POSS with well-defined organic/inorganic hybrid constituents had received considerable interest due to its unique cage like molecular structure and interesting physicochemical properties. ${ }^{17,18}$ Having eight organic groups surrounding a cagelike core connected by Si-O-Si bonds, POSS was highly soluble in many kinds of organic solvents. ${ }^{19}$ In this article, we employed a covalent functionalization approach to obtain oil dispersible GO using aminopropylisobutyl polyhedral oligomeric silsesquioxane (POSS- $\mathrm{NH}_{2}$ ) as modifier (Fig. 1). The hybrid structures of POSS-GO consisting of a plurality of hydrophobic isobutyl 

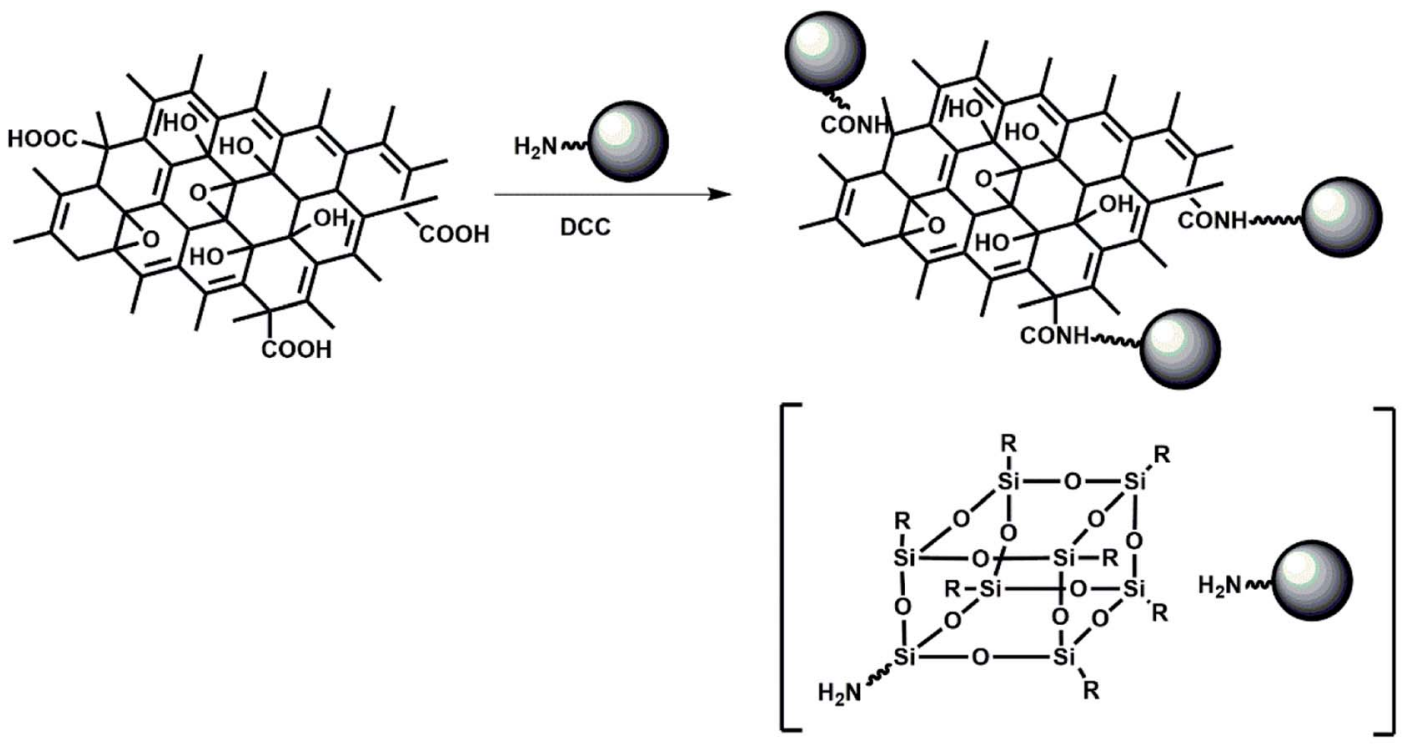

Aminopropylisobutyl polyhedral oligomeric silses quioxane (POSS- $\mathrm{NH}_{2}$ )

Fig. 1 Schematic representation of the route to POSS-modified graphene (POSS-GO).

groups, making it dispersible in many organic solvent. ${ }^{20}$ The resultant POSS-GO nanocomposite was then thoroughly characterized using FTIR, XPS, Raman spectroscopy, TEM and SPM, respectively. The frictional performance of synthetic base oil with various concentrations of POSS-GO was evaluated by UMT3 tribometer, and the 3D laser scanning confocal microscopy, scanning electron microscope (SEM) were used to characterize the worn surface. Finally, the Raman spectroscopy and TEM were used to study the friction and wear mechanisms.

\section{Experimental section}

\section{Material}

Powders of GO were purchased from Shanghai ASHINE Technology Development Co. Ltd. The base oil was GTL8 from Shell. All other reagents were purchased from Aldrich and used directly without further purification.

\section{Preparation of POSS-GO}

POSS-GO was prepared according to the reported literature. In a $250 \mathrm{~mL}$ round-bottom flask, $100 \mathrm{mg}$ of graphene oxide, $2 \mathrm{~g}$ of POSS- $\mathrm{NH}_{2}$, and $100 \mathrm{mg}$ of DCC (as a catalyst) were dissolved in $50 \mathrm{~mL}$ of THF. Ultrasonic for 20 minutes to make it evenly dispersed. Then, the mixture was refluxed for 48 hours and the solution was evaporated to further heat treated at a temperature of $120{ }^{\circ} \mathrm{C}$ for 8 hours. The solid product was then dissolved in $50 \mathrm{~mL}$ of THF and precipitated with $500 \mathrm{~mL}$ of methanol. This process was repeated 3 times in order to remove unreacted POSS- $\mathrm{NH}_{2}$. The last step was to vacuum filter the methanol solution with a $0.22 \mu \mathrm{m}$ PVDF membrane. After filtration, the solid product was placed in an $80{ }^{\circ} \mathrm{C}$ oven and dried to collect the final product.

\section{Characterization}

The GO and POSS-GO were characterized by transmission electron microscopy (TEM, JEOL2100), field-emission scanning electron microscopy (SEM, S4800, Hitachi) and Fourier-transform infrared spectroscopy (FTIR, Thermo). The layer thickness of GO was characterized Scanning probe microscope (SPM, FEI, USA). The wear scar diameters on the steel balls were measured using an optical microscope. The wear track profiles of the $316 \mathrm{~L}$ were obtained using a laser scanning microscope. The wear rate was calculated by the Surface profiler (ASTQ, USA). The changes in microstructure and chemical composition of the nanofluids were investigated via Raman spectroscopy (RENISHAW, Renishaw) and X-ray photoelectron spectroscopy (XPS, AXIS ULTRA DLD, USA) respectively. The binding energy were referenced to the $\mathrm{C} 1 \mathrm{~s}$ line at $284.8 \mathrm{eV}$. The microstructure of the GO and POSS-GO after friction testing was characterized via TEM. The oil/POSS-GO on the wear track after friction testing were collected by microsyringe and repeated washed with ethyl alcohol by ultrasonication for a long time. The suspension was then dropped on lacy carbon-coated $\mathrm{Cu}$ grid for TEM observations.

\section{Friction and wear test}

Different concentrations of POSS-GO were separately dispersed into oil through ultrasonication for 2 hours to obtain a series of homogeneous and dark suspensions. The resulting nanofluids were coated on 316L. The interaction between the 316L and upper oil film was mainly physical adsorption. All friction tests were conducted on the ball-on-disk tribometer in UMT-3. Commercially available steel balls (GCr15) with a diameter of $6 \mathrm{~mm}$ were used as the counterparts. Sliding experiments were performed with different loading force $(10 \mathrm{~N}, 20 \mathrm{~N})$ and same frequency $(2 \mathrm{~Hz})$. Each friction test lasted $30 \mathrm{~min}$ and recorded as the average value. In addition, half an hour-long friction tests were carried out for getting wear rate, Raman spectra and TEM images of the debris. 

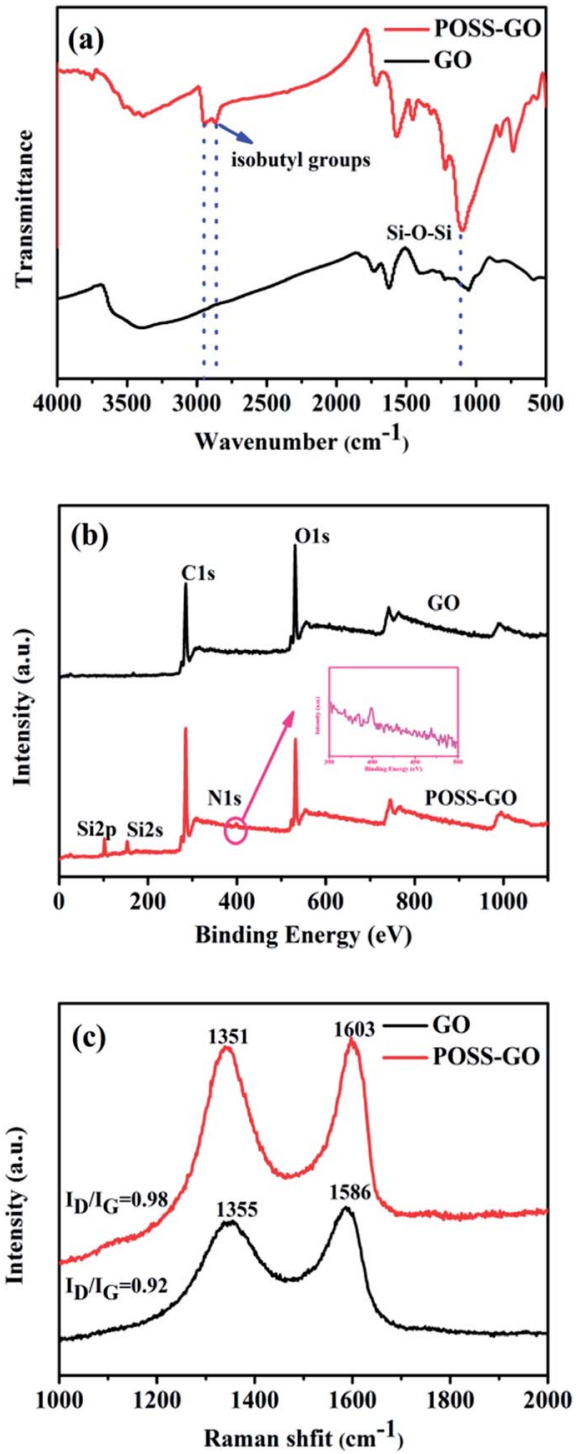

Fig. 2 Characterization of POSS-GO. (a) FTIR spectra of GO and POSS-GO samples; (b) Raman spectra of GO, POSS-GO; (c) XPS survey spectra of the GO and POSS-GO.

\section{Results and discussion}

\section{Preparation and characterization of POSS-GO}

$\mathrm{GO}$, a product of chemical oxidation and exfoliation of graphite powders, consists of many abundant functional groups such as hydroxy, carboxylic acid and epoxide. These functional groups can not only prevent the aggregation of GO from stacking but also can serve as reactive sites for further functionalization. This work primarily focused on improving the dispersion of GO in lubricating oil via surface linkage of amine-capped POSS (Fig. 1). The resultant POSS-GO nanocomposite was then characterized using FTIR, XPS, Raman spectroscopy, TEM and SPM, to better understand its structures and functionalities.

FTIR spectra of the graphene oxide and POSS-GO hybrid were shown in Fig. 2a. As expected, the FTIR spectrum of graphene oxide exhibited strong characteristic bands at 3421, 1732, $1621,1373,1263$ and $1064 \mathrm{~cm}^{-1}$, demonstrating the presence of hydroxyl, carbonyl, epoxy, phenol groups. ${ }^{21}$ The intensities of these FTIR peaks decreased significantly after chemical attachment of POSS onto the GO surface. In addition, the strong characteristic band at $1110 \mathrm{~cm}^{-1}$ associated with the $\mathrm{Si}-\mathrm{O}-\mathrm{Si}$ stretching band and the relatively weak bands over 2750$3000 \mathrm{~cm}^{-1}$ derived from the isobutyl groups in POSS were clearly seen in the FTIR spectrum of POSS-GO, indicating that POSS had been chemically grafted onto GO.

X-ray photoelectron spectroscopic (XPS) measurements were performed to gain further insights into the chemical changes of surface associated with the reaction. As expected, only C 1s and O 1s peaks were seen in the XPS survey spectrum for GO (Fig. 2b). The appearance of the Si 2p (101 eV), Si 2s (152 eV), and $\mathrm{N} 1 \mathrm{~s}(399.5 \mathrm{eV})$ peaks, accompanied by the reduced $\mathrm{O} 1 \mathrm{~s}$ peak with respect to the $\mathrm{C} 1 \mathrm{~s}$ peak in the XPS survey spectrum of POSS-GO indicated the successfulness of the covalent bonding of POSS onto GO.

The structure changes of GO before and after graft with POSS were also investigated by Raman spectroscopy. Two distinct peaks at 1348 and $1575 \mathrm{~cm}^{-1}$ (Fig. 2c) were assigned to D and G bands, which represent the vibration of $\mathrm{sp}^{3}$ carbon atoms from the functional groups and the in-plane vibration of $\mathrm{sp}^{2}$ carbons.

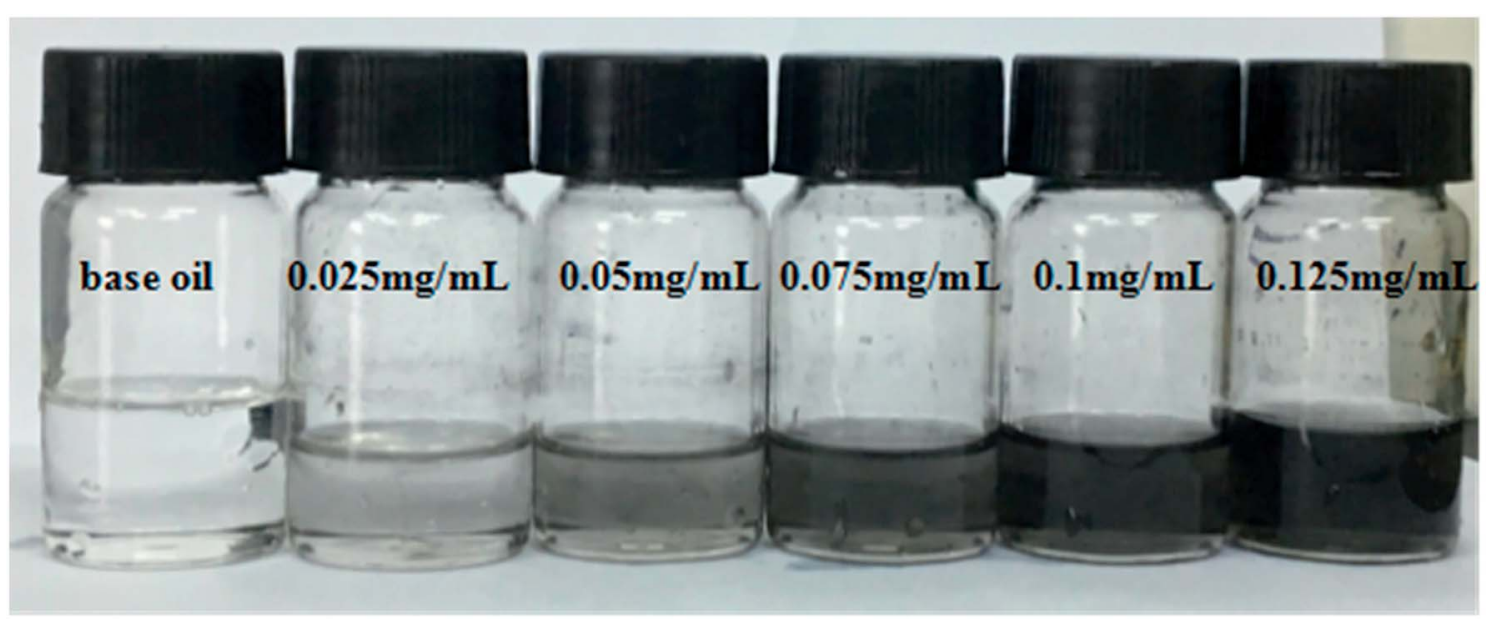

Fig. 3 Digital images of oil/POSS-GO with concentrations ranging from 0 to $0.125 \mathrm{mg} \mathrm{mL}^{-1}$ (from left to right). 

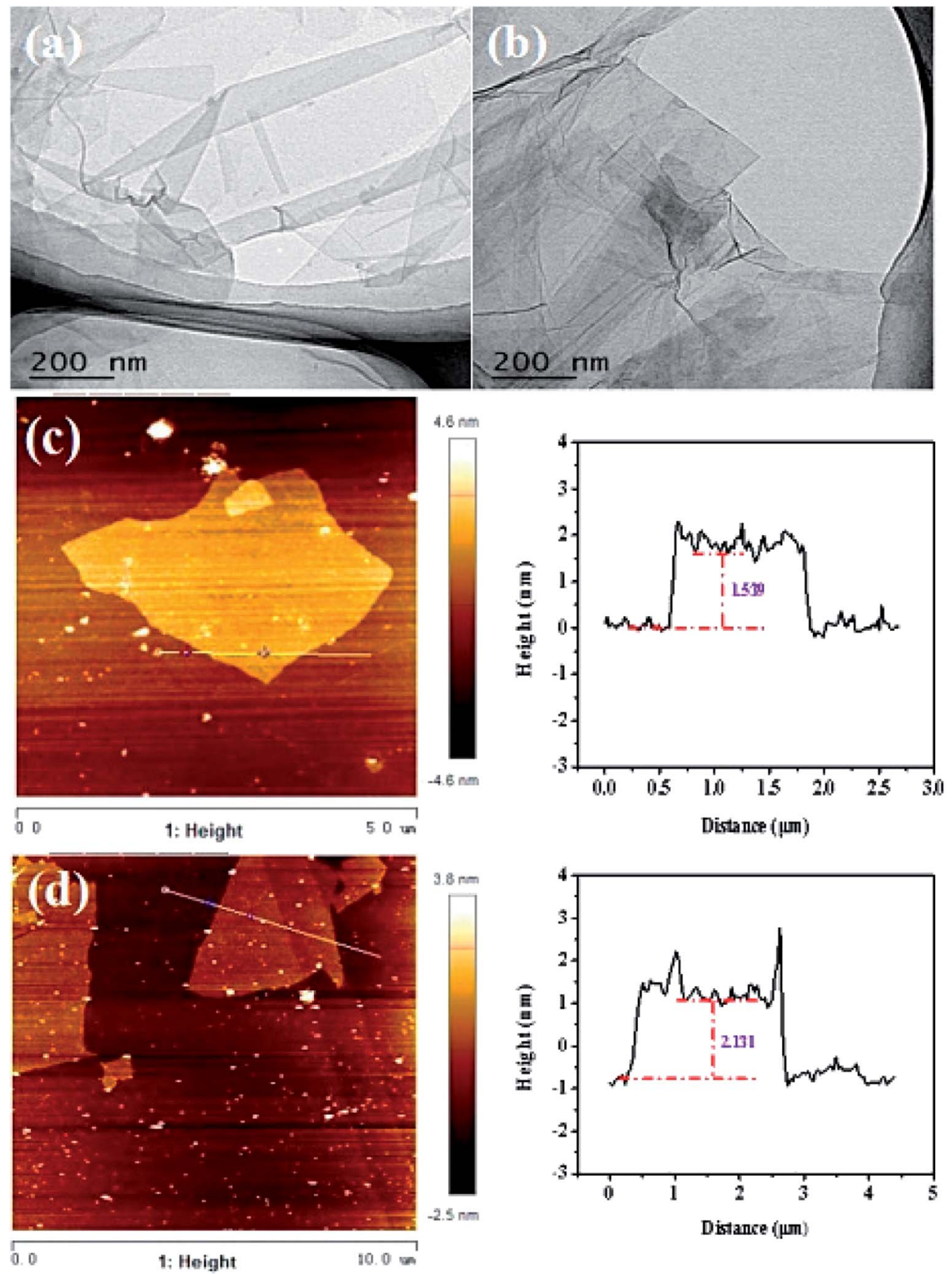

Fig. 4 Morphology of POSS-GO. TEM image (a) GO, (b) POSS-GO; (c) SPM images of GO with height profiles (d) POSS-GO with height profiles.

The intensity ratio of $\mathrm{D}$ and $\mathrm{G}$ bands $\left(I_{\mathrm{D}} / I_{\mathrm{G}}\right)$ was usually employed to estimate the disordered level of the graphene crystal structure. ${ }^{22}$ It was obvious that the ratio of intensity value increased from 0.92 to 0.98 after POSS functionalization, which signified the higher disorder level of POSS-GO.

For tribological application, nano-structured materials should be thoroughly dispersed in the lube oil to ensure efficient lubrication. The POSS-GO was dispersed in the base oil after sonication. It was observed that no apparent agglomeration was observed in $24 \mathrm{~h}$ with a concentration up to $0.125 \mathrm{mg}$
$\mathrm{mL}^{-1}$ (Fig. 3). The microstructures of the POSS-GO were observed with the TEM and SPM. Both GO before and after modification exhibited typical lamellar structure with obvious wrinkles, corrugations and scrolled morphology (Fig. 4a and b), indicating the existence of few layers graphene. The typical SMP images clearly reveals thickness of GO was about $1.53 \mathrm{~nm}$ and the calculated layers of graphene sheets were $4-5$ (Fig. $4 \mathrm{c}$ and d). The POSS modified GO was $2.12 \mathrm{~nm}$, which was obviously larger than that of GO due to the presence of bulky POSS on the surface of GO. 

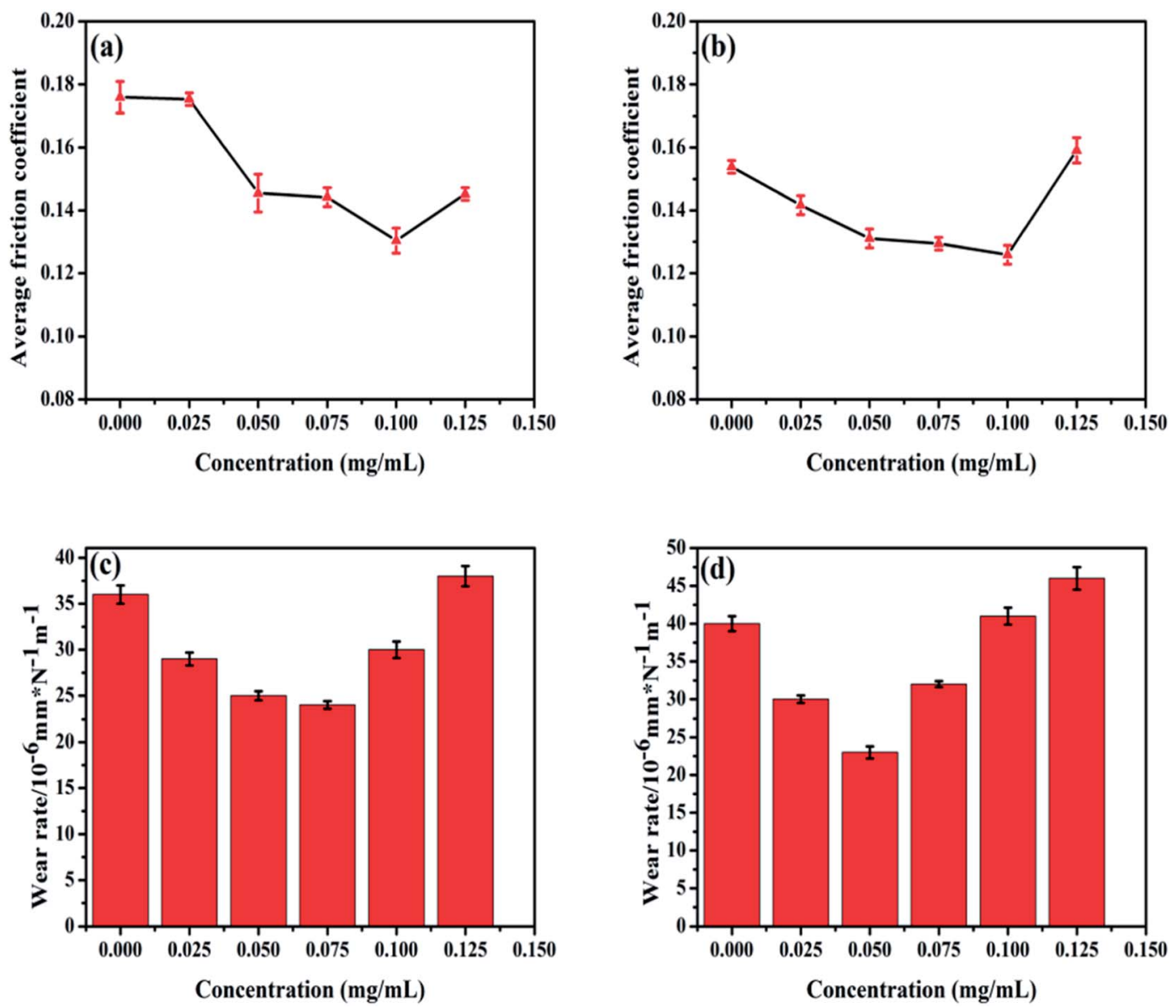

Fig. 5 Friction and wear of oil lubricants with different concentration of POSS-GO lubricated at frequency $2 \mathrm{~Hz}$ under different load at ambient environment. (a) Friction coefficient under $10 \mathrm{~N}$; (b) friction coefficient under $20 \mathrm{~N}$; (c) disk wear rate under $10 \mathrm{~N}$; (d) disk wear rate under $20 \mathrm{~N}$.

\section{Lubrication properties of POSS-GO additives in base oil}

For estimation of the tribological properties of base oil containing POSS-GO additives, UMT-3 tribology tester was employed to test the friction and coefficient and surface profile was used to get the wear rate of the surface. The concentration dependent trend of friction coefficient and wear rate under loading force of 10 and $20 \mathrm{~N}$ at $2 \mathrm{~Hz}$ frequency and 30 minutes are shown in Fig. 5 . The average friction coefficient of base oil was 0.176 under the load of $10 \mathrm{~N}$. The reduction of friction coefficient was significant with the addition of POSS-GO, and the optimized concentration of POSS-GO was $0.1 \mathrm{mg} \mathrm{mL}^{-1}$, exhibiting the lowest of friction coefficient of 0.130 with a reduction up to $26 \%$. The friction coefficient was found to be 0.153 under the load of $20 \mathrm{~N}$, and it was reduced to around 0.130 at the concentration of POSS-GO ranging from $0.05-0.1 \mathrm{mg}$ $\mathrm{mL}^{-1}$. It was worth to mention that the friction coefficient was up to 0.159 at the POSS-GO concentration of $0.125 \mathrm{mg} \mathrm{mL}^{-1}$, which was even larger to that of neat oil. The wear rate under $10 \mathrm{~N}$ and $20 \mathrm{~N}$ were shown Fig. $5 \mathrm{c}$ and d, which was calculated from wear depth after friction experiment, and was calculated from wear depth by ref. 23 .

$$
w=\frac{V}{F L}
$$

where $V$ was the total friction volume, $F$ was the normal load and $L$ was the total distance. It was found that the lowest wear rate was found at a concentration of $0.075 \mathrm{mg} \mathrm{mL}^{-1}$ under the load of $10 \mathrm{~N}$ (reduction by 33\%), whereas the wear rate was optimal at $0.05 \mathrm{mg} \mathrm{mL}^{-1}$ under the load of $20 \mathrm{~N}$ (reduction by $43 \%)$. It could be concluded from the above results that the concentrations of POSS-GO additives in the base oil was an important factor for decrease in friction coefficient and wear of the lubricated solid contacts. The lubricating effect of POSS-GO was not apparent at lower and higher concentrations, exhibiting relative higher friction and wear. At the optimum concentration of POSS-GO graphene, graphene nanosheets could form a boundary tribofilm in the contract, resulting in reduction of friction coefficient. However, high concentration of POSS-GO led to aggregation of graphene nanosheets in the contract, and further weakening the lubricating effect of POSS-GO.

A laser scanning microscope was used to investigate the wear morphology after friction test. Micrographs and profiles of wear scars on the disk lubricated at the frequency of $2 \mathrm{~Hz}$ and load of $10 \mathrm{~N}$ using GCr15 ball and 316L disk are shown in Fig. 6, and the optical micrographs of wear scar of steel balls are shown in Fig. 7. A wear track with the cross-section area of $1260 \mu \mathrm{m}^{2}$ and width of $745 \mu \mathrm{m}$ was formed for base oil. It was apparent that 
(a)
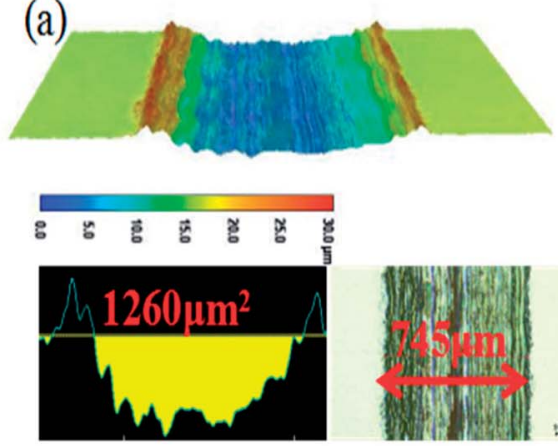

(d)
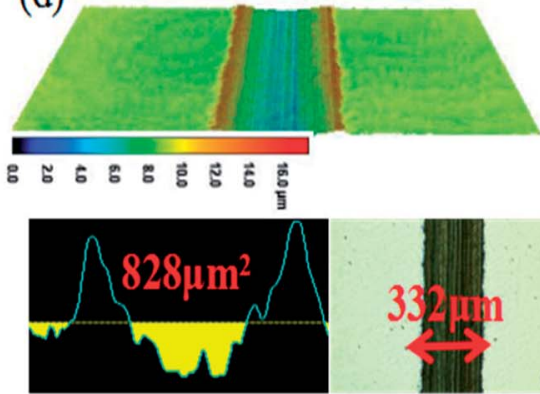

(b)

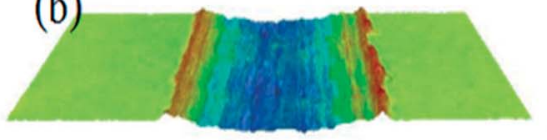

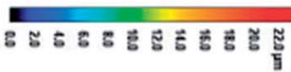
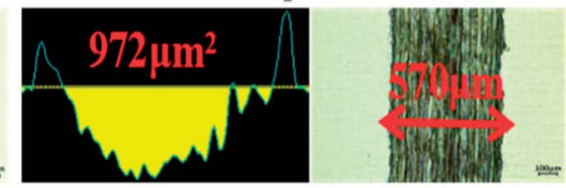

(e)

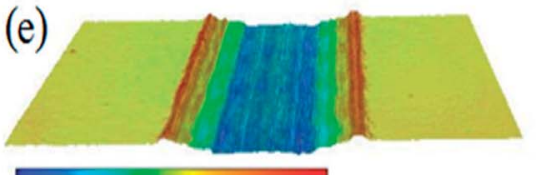

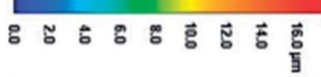

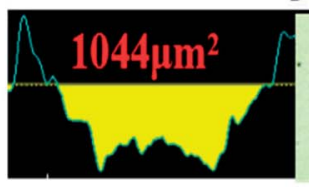

(c)
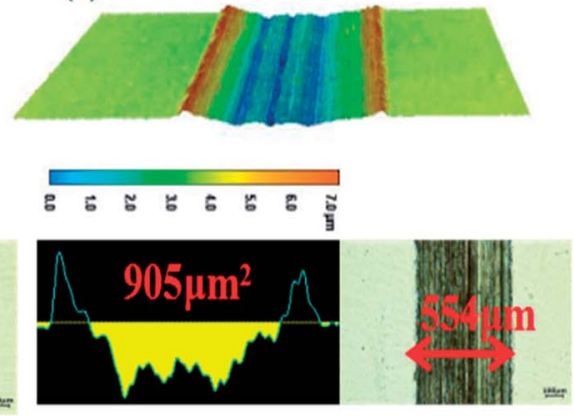

(f)

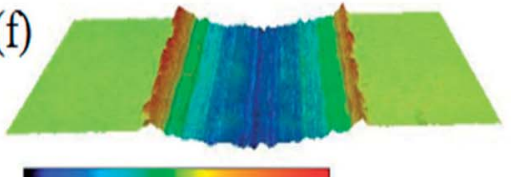

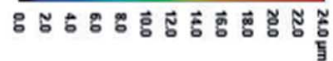
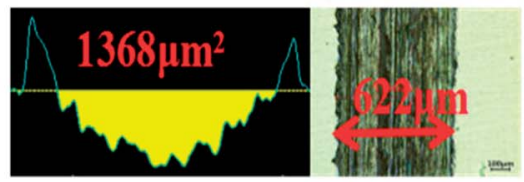

Fig. 6 Micrographs and profiles of wear scars on the disk lubricated at frequency $2 \mathrm{~Hz}$ under $10 \mathrm{~N}$ load at ambient environment with GCr15 ball and 316L disk. (a) Pure oil (b) $0.025 \mathrm{mg} \mathrm{mL}^{-1}$ POSS-GO; (c) $0.05 \mathrm{mg} \mathrm{mL}^{-1}$ POSS-GO; (d) $0.075 \mathrm{mg} \mathrm{mL}^{-1} \mathrm{POSS}-\mathrm{GO}$; (e) $0.1 \mathrm{mg} \mathrm{mL}^{-1} \mathrm{POSS}-\mathrm{GO}$; (f) $0.125 \mathrm{mg} \mathrm{mL}^{-1}$ POSS-GO.

the depth and width of the wear scar of steel disk varied with the POSS-GO concentration in the lubricating oil from the 3D surface profiler images of the 316L. The obtained results showed that the specimen with lower friction coefficient and wear rate exhibited the wear track with smaller cross-section area and width. A wear track with the smallest area of 828 $\mu \mathrm{m}^{2}$ and width of $332 \mu \mathrm{m}$ was observed at the concentration of $0.075 \mathrm{mg} \mathrm{mL}^{-1}$ POSS-GO. Fig. 8 shows the optical micrographs
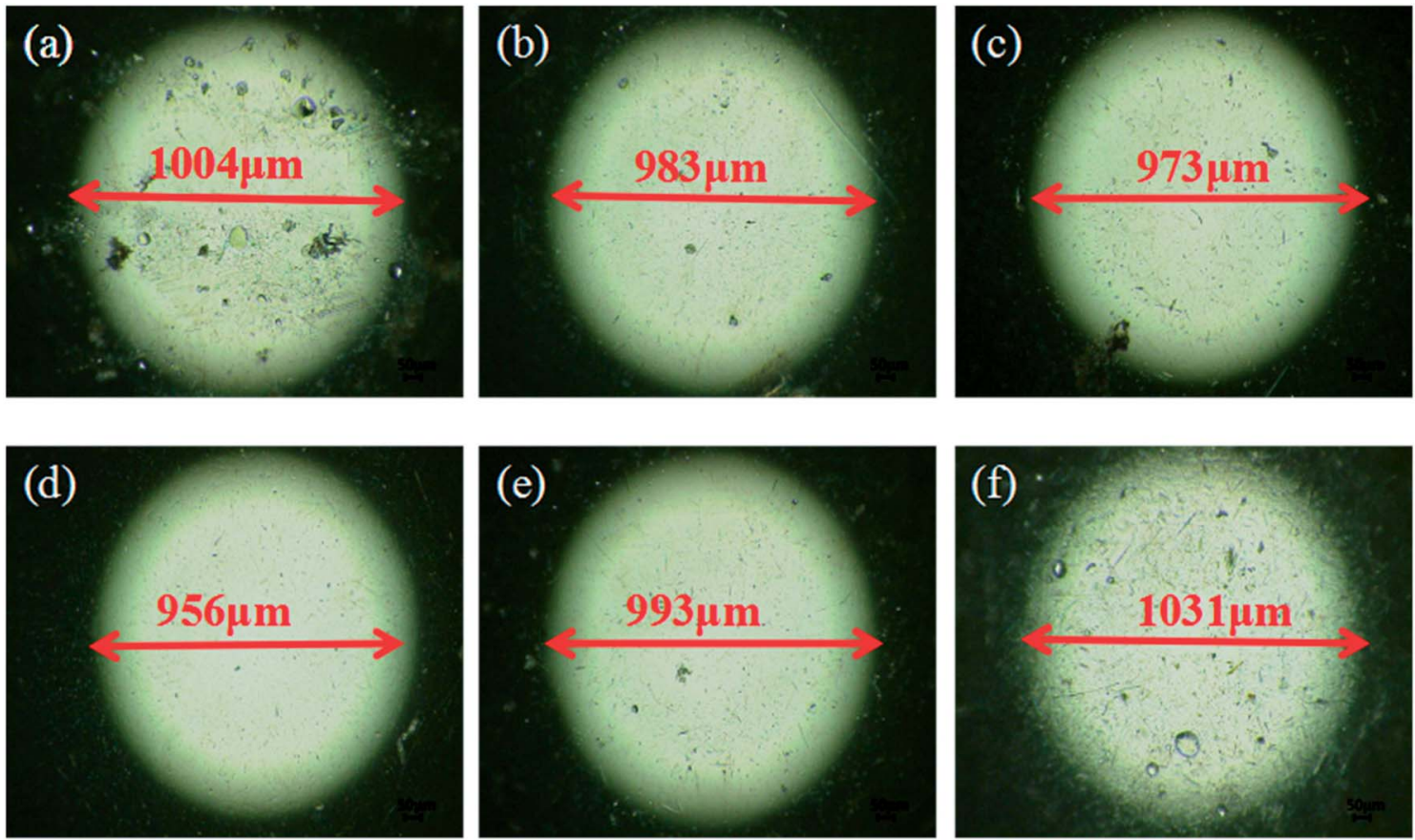

Fig. 7 Optical micrographs of wear scar of steel balls after 30 min of friction testing at a load of $10 \mathrm{~N}$ and frequency $2 \mathrm{~Hz}$ : (a) pure oil; (b) $0.025 \mathrm{mg}$ mL $\mathrm{mL}^{-1}$ POSS-GO; (c) 0.05 mg mL ${ }^{-1}$ POSS-GO; (d) $0.075 \mathrm{mg} \mathrm{mL}^{-1}$ POSS-GO; (e) $0.1 \mathrm{mg} \mathrm{mL}^{-1}$ POSS-GO; (f) $0.125 \mathrm{mg} \mathrm{mL}^{-1}$ POSS-GO. 

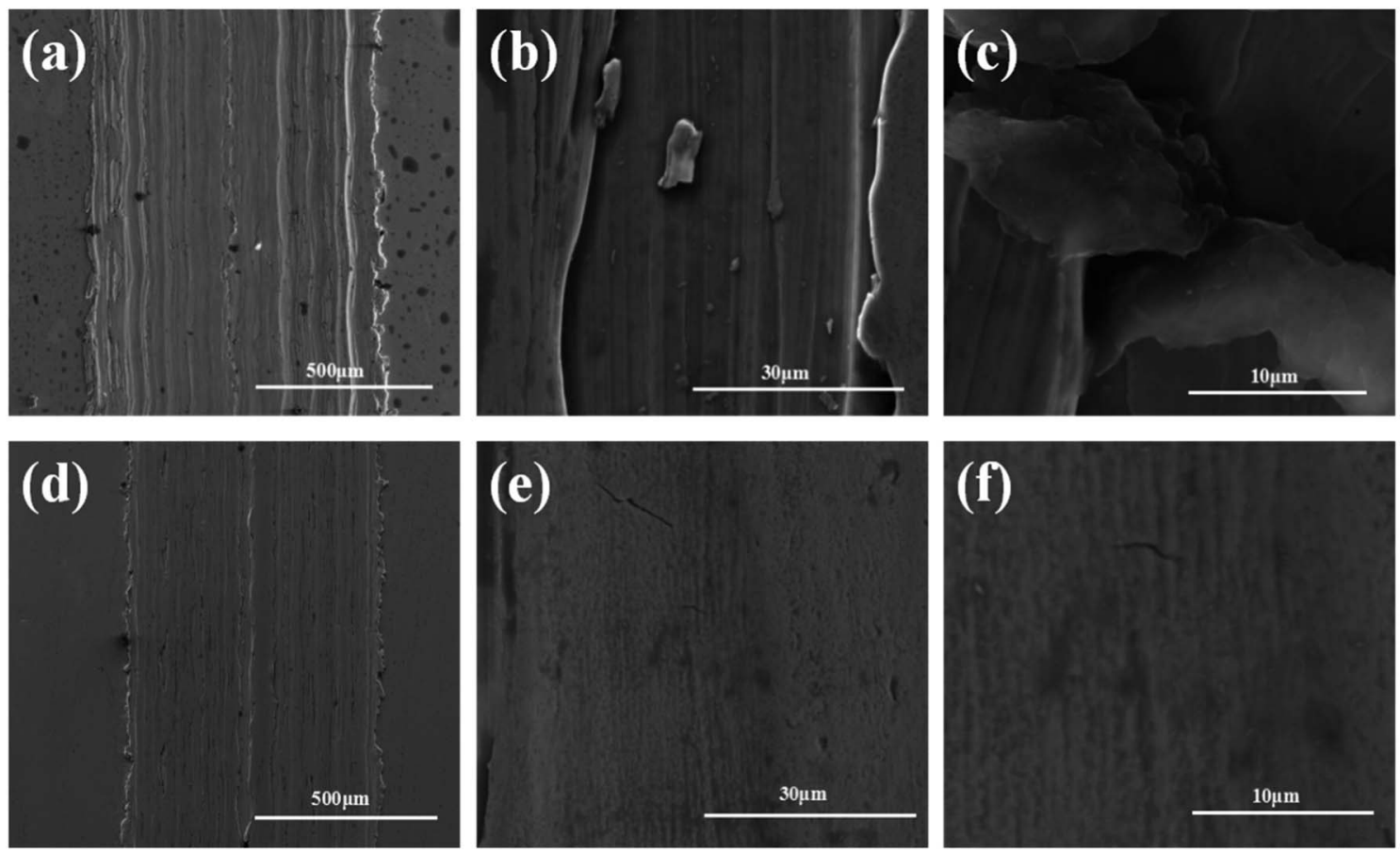

Fig. 8 SEM images of $316 \mathrm{~L}$ after friction. Pure oil $(a-c)$ and oil containing $0.05 \mathrm{mg} \mathrm{mL}^{-1}$ POSS-GO (d-f).

of wear scar of steel balls after 30 min of friction test. It was found that the spot diameter decreased from $1004 \mu \mathrm{m}$ (neat oil) to $956 \mu \mathrm{m}\left(0.075 \mathrm{mg} \mathrm{mL}^{-1}\right.$ of POSS-GO), also well correlated with the above friction test results.

\section{Worn surface analysis}

It has been reported that the adsorbed graphene tribofilm formation in the contact played the key role for the reduction in friction and wear. ${ }^{24,25}$ For confirmation of the attachment of POSS-GO on the steel surface, the surface topography of wear scar was examined by SEM. The wear scar of steel without POSSGO and $0.075 \mathrm{mg} \mathrm{mL}^{-1}$ of POSS-GO were shown in Fig. 8. The wear surface from base oil had deep wear ditch, demonstrating a abrasive wear without efficient lubrication. Hence, the friction between the GCr15 friction ball and the hard protrusions on the 316L caused serious material loss. On the contrary, the wear scar in presence of $0.075 \mathrm{mg} \mathrm{mL}{ }^{-1}$ of POSS-GO showed a smaller and shallower ditch. Through local enlargement, there was almost no ditch, the addition of $0.075 \mathrm{mg} \mathrm{mL}^{-1}$ POSSGO made the wear of friction balls and 316L into a slight adhesive wear. The deposited graphene sheets on wear surface formed a physical film that filled the furrow of the worn surface, and improved the finish of the worn surface.

Raman spectra of wear scar provided further proof of graphene tribofilm formation on steel surface as shown in Fig. 9. The specimen in presence of POSS-GO additives had obvious D and $\mathrm{G}$ bonds, which were the characteristic peaks of graphene. ${ }^{26,27}$ It shown that POSS-GO could stably exist on the wear surface during friction. The combined Raman charts and the above friction effect demonstrated that the 316 stainless steel surface had the effect of anti-wear lubrication because the POSS-GO adhered to the wear mark and exhibited excellent tribological properties at a certain concentration. ${ }^{28,29}$ Based on the above friction experiment and in the entire experiment, POSS-GO played an effective lubricating effect between solid body contacts. ${ }^{30,31}$

TEM images of POSS-GO before and after friction testing under the load of $10 \mathrm{~N}, 20 \mathrm{~N}$ at the frequency of $2 \mathrm{~Hz}$ are shown in Fig. 10. It has been reported graphene wrinkles are less conducive to shear sliding between layers. ${ }^{31}$ At the beginning of the friction test, the graphene layer forms an early transfer film, avoiding direct contact between the two dual surfaces. Graphene oxide sheet had a certain bearing role. In the rubbing process, graphene sheets become thicker and thicker, graphene acted as nano-bearings between pairs. ${ }^{32}$ At lower load, the graphene sheet broke into small pieces, and at high load, graphene

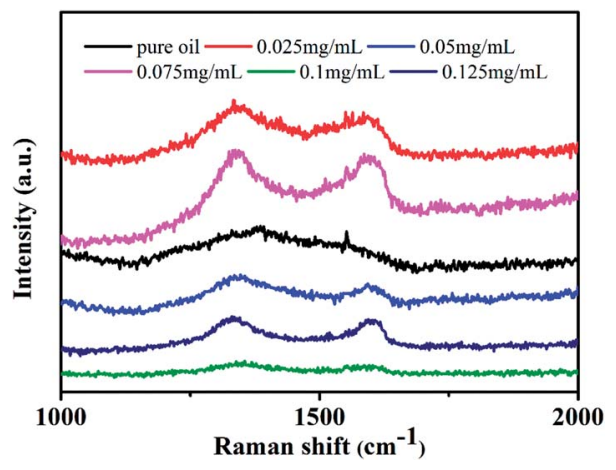

Fig. 9 Raman spectra of the wear scar of $316 \mathrm{~L}$ after friction testing under an applied load of $10 \mathrm{~N}$. (a) $0.025 \mathrm{mg} \mathrm{mL}^{-1}$ POSS-GO (black line) and pure oil (red line); $0.05 \mathrm{mg} \mathrm{mL}^{-1}$ POSS-GO (black line) and pure oil (red line); $0.75 \mathrm{mg} \mathrm{mL}^{-1}$ POSS-GO (black line) and pure oil (red line); $0.1 \mathrm{mg} \mathrm{mL}^{-1}$ POSS-GO (black line) and pure oil (red line); $0.125 \mathrm{mg}$ $\mathrm{mL}^{-1}$ POSS-GO (black line) and pure oil (red line). 

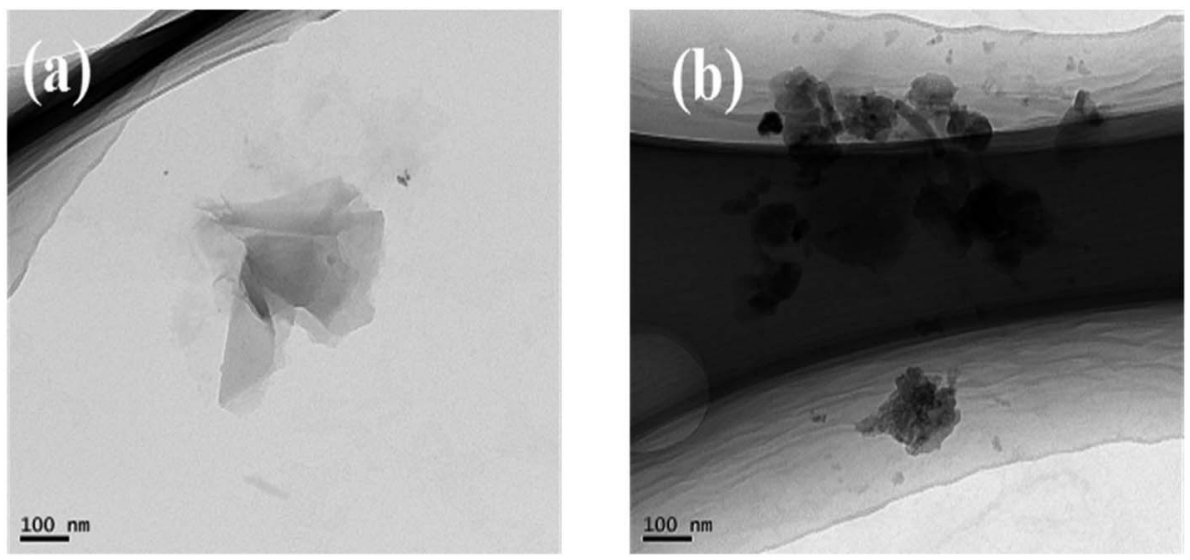

Fig. 10 Typical TEM images of (a) POSS-GO after friction testing under the load of $10 \mathrm{~N}$ and frequency $2 \mathrm{~Hz}$; (b) oil/POSS-GO after friction testing under the load of $20 \mathrm{~N}$ at frequency of $2 \mathrm{~Hz}$.

sheets stacked into a thicker graphene layers on contact surfaces. The load resulted in different morphology of graphene sheets and therefore showed different tribological properties at given POSS-GO concentrations. ${ }^{33,34}$

\section{Conclusion}

POSS-GO was successfully synthesized by covalently linkage of amine-capped POSS and graphene oxide and exhibited excellent dispersibility in synthetic base oil. Experimental study of the effect of POSS-GO on the friction coefficient and wear of synthetic base oil using UMT tester showed that the concentrations of POSS-GO additives in the base oil is an important aspect for decreasing the friction and wear of the lubricated solid contacts. At lower and higher concentrations of POSS-GO, the lubricating effect was not effective or even worse. In contrast, at optimized concentration of POSS-GO, graphene nanosheets could form a boundary tribofilm between the contract, resulting in reduction of friction coefficient and wear. The remarkable reductions in friction are attributed to the different microstructural variations of GO during the friction process. Under the load of $10 \mathrm{~N}$, the average friction coefficient was reduced by $26 \%$ and wear rate was reduced by $33 \%$ at the concentration of $0.075 \mathrm{mg} \mathrm{mL}{ }^{-1}$ of POSS-GO. The facile dispersible POSS-GO revealed its potential as nanoadditive for lubricating applications.

\section{Conflicts of interest}

There are no conflicts to declare.

\section{Acknowledgements}

The authors gratefully acknowledge financial support provided by the National Natural Science Foundation of China (51775282, 51705511), Zhejiang Provincial Natural Science Foundation (LZ17E050004), Natural Science Foundation of Jiangsu Province (BK20151519).

\section{Notes and references}

1 A. Z. Syahir, N. W. M. Zulkifli, H. H. Masjuki, M. A. Kalam, A. Alabdulkarem, M. Gulzar, L. S. Khuong and M. H. Harith, J. Cleaner Prod., 2017, 168.

2 Y. Wu, X. Zeng, T. Ren, E. D. Vries and E. V. D. Heide, Tribol. Int., 2017, 105, 304-316.

3 R. C. Schlicht, 1983.

4 G. Zhang, Y. Xu, X. Xiang, G. Zheng, X. Zeng, Z. Li, T. Ren and Y. Zhang, Tribol. Int., 2018, 39-48.

5 X. Yang, Y. Meng and Y. Tian, Tribol. Lett., 2014, 56, 161-169. 6 Y. Hu, Y. Wang, Z. Zeng, H. Zhao, X. Ge, K. Wang, L. Wang and Q. Xue, Carbon, 2018, 41-48.

7 D. Berman, A. Erdemir and A. V. Sumant, Carbon, 2013, 54, 454-459.

8 Z. L. Cheng, W. Li, P. R. Wu and Z. Liu, J. Alloys Compd., 2017, 722.

9 Z. Xu, X. Shi, W. Zhai, J. Yao, S. Song and Q. Zhang, Carbon, 2014, 67, 168-177.

10 X. Gao, H. Yue, E. Guo, S. Zhang, L. Yao, X. Lin, B. Wang and E. Guan, J. Mater. Sci. Technol., 2018, in press.

11 K. Hou, J. Wang, Z. Yang, L. Ma, Z. Wang and S. Yang, Carbon, 2017, 115, 83-94.

12 Y. Xu, Y. Peng, K. D. Dearn, X. Zheng, L. Yao and X. Hu, Wear, 2015, s342-343, 297-309.

13 S. Y. Yang, W. N. Lin, Y. L. Huang, H. W. Tien, J. Y. Wang, C. C. M. Ma, S. M. Li and Y. S. Wang, Carbon, 2011, 49, 793-803.

14 X. Dou, A. R. Koltonow, X. He, H. D. Jang, Q. Wang, Y. W. Chung and J. Huang, Proc. Natl. Acad. Sci. U. S. A., 2016, 113, 1528.

15 J. Lin, L. Wang and G. Chen, Tribol. Lett., 2011, 41, 209-215. 16 Y. Peng, Z. Wang and K. Zou, Langmuir, 2015, 31, 7782-7791. 17 S. H. Phillips, T. S. Haddad and S. J. Tomczak, Curr. Opin. Solid State Mater. Sci., 2004, 8, 21-29.

18 Y. Xue, H. Wang, D. Yu, L. Feng, L. Dai, X. Wang and T. Lin, Chem. Commun., 2009, 42, 6418.

19 Y. Xue, H. Wang, Y. Zhao, L. Dai, L. Feng, X. Wang and T. Lin, Adv. Mater., 2010, 22, 4814-4818. 
20 Y. Xue, Y. Liu, F. Lu, J. Qu, H. Chen and L. Dai, J. Phys. Chem. Lett., 2012, 3, 1607-1612.

21 A. Lerf, H. He, A. Michael Forster and J. Klinowski, J. Phys. Chem. B, 1998, 102, 4477-4482.

22 K. K. Mishra, K. Panda, N. Kumar, D. Malpani, T. R. Ravindran and O. P. Khatri, J. Ind. Eng. Chem., 2017, 97-105.

23 A. M. Häger and M. Davies, Compos. Mater., 1993, 8, 107-157.

24 J. Mao, J. Zhao, W. Wang, Y. He and J. Luo, Tribol. Int., 2017, 119.

25 L. Mu, Y. Shi, X. Guo, Z. Wei, L. Chen, T. Ji, H. Jing, H. Wang and J. Zhu, J. Colloid Interface Sci., 2017, 498, 47-54.

26 F. Tuinstra and J. L. Koenig, J. Chem. Phys., 1970, 53, 11261130.

27 A. C. Ferrari, J. C. Meyer, V. Scardaci, C. Casiraghi, M. Lazzeri, F. Mauri, S. Piscanec, D. Jiang, K. S. Novoselov and S. Roth, Phys. Rev. Lett., 2006, 97, 187401.
28 P. Delhaes, M. Couzi, M. Trinquecoste, J. Dentzer, H. Hamidou and C. Vix-Guterl, Carbon, 2006, 44, 3005-3013.

29 J. Chen, L. Chen, Z. Zhang, J. Li, L. Wang and W. Jiang, Carbon, 2012, 50, 1934-1941.

30 P. Wu, X. Li, C. Zhang, X. Chen, S. Lin, H. Sun, C. T. Lin, H. Zhu and J. Luo, ACS Appl. Mater. Interfaces, 2017, 9, 21554-21562.

31 X. Zhi, J. Liu, J. Xing and S. Ma, Mater. Sci. Eng., A, 2014, 603, 98-103.

32 L. Zhang, J. Pu, L. Wang and Q. Xue, ACS Appl. Mater. Interfaces, 2015, 7, 8592.

33 L. Zhang, J. Pu, L. Wang and Q. Xue, Carbon, 2014, 80, 734745.

34 X. Liu, J. Pu, L. Wang and Q. Xue, J. Mater. Chem. A, 2013, 1, 3797-3809. 